\title{
A role of expression level of reference and investigated genes in prostate tumors for $q \mathrm{PCR}$ analysis
}

\author{
G. V. Gerashchenko ${ }^{1}$, E. O. Stakhovsky ${ }^{2}$, L. I. Chashchina ${ }^{1}$, \\ O. P. Gryzodub ${ }^{3}$, V. I. Kashuba ${ }^{1}$ \\ ${ }^{1}$ Institute of Molecular Biology and Genetics, NAS of Ukraine \\ 150, Akademika Zabolotnoho Str., Kyiv, Ukraine, 03680 \\ ${ }^{2}$ National Cancer Institute, \\ 33/43, Lomonosova Str., Kyiv, Ukraine, 03022 \\ ${ }^{3}$ State Institution «Institute of Urology of NAMS of Ukraine» \\ 9-a, Yu. Kotsubyns'koho Str., Kyiv, Ukraine, 04053 \\ g.v.gerashchenko@imbg.org.ua
}

\begin{abstract}
Aim. To determine the expression profiles of a set of cancer-associated genes in prostate tumors, using various normalization protocols (with 1,2 and 4 reference genes) and to optimize a combination of reference genes to calculate the relative expression (RE) of the investigated genes in prostate cancers. Methods. Relative expression level of 23 genes was analyzed by quantitative PCR (qPCR) in 37 prostate cancer tissues (T) with different Gleason scores (GL) and at various stages and compared with 37 corresponding normal prostate tissue (CNT) samples and with 20 samples of prostate adenomas. Results. Theoretical calculations of the $\mathrm{RE}$ deviation showed no influence of the normalization protocols on the results for both the reference and the investigated genes. The experimental data that were calculated using a 2- $\Delta \Delta \mathrm{Ct}$ showed statistically significant differences in the expression of 17 out of 23 investigated genes, when the paired T/CNT were compared. RE values calculated using the $2^{-\Delta \mathrm{Ct}}$ method showed a high similarity of statistical data in all reference gene groups for tumor-CNT-adenoma groups (> $82 \%$ ). Data grouping by a cancer stage showed $69 \%$, and by the GL score $-64.5 \%$ of the data overlapping. Conclusions. All three types of normalization protocols, as expected, can be used for RE normalization in prostate tumor samples. The usage of either the $2^{-\Delta \mathrm{Ct}}$ or $2^{-\Delta \Delta \mathrm{Ct}}$ models showed no difference in the calculated RE levels for the studied reference genes. The most important factor was the constitutive expression of the reference genes. Moreover, the expression levels of the investigated genes, changes in RE values, number of samples in groups and heterogeneity of gene expression are important parameters for the selection of the threshold in expression level differences between groups for a reliable data interpretation.
\end{abstract}

Keywords: prostate tumors, relative expression, reference genes validation, expression level, genes expressed at low levels.

(C) 2018 G. V. Gerashchenko et al.; Published by the Institute of Molecular Biology and Genetics, NAS of Ukraine on behalf of Biopolymers and Cell. This is an Open Access article distributed under the terms of the Creative Commons Attribution License (http://creativecommons.org/licenses/by/4.0/), which permits unrestricted reuse, distribution, and reproduction in any medium, provided the original work is properly cited 


\section{Introduction}

A quantitative real-time PCR (qPCR) is a widely used method to assess the gene expression in a basic and clinical research [1-3]. Relative quantification requires the use of a reference gene (or a few reference genes) for normalization of the gene expression. Usually, several housekeeping genes are used for this purpose [4]. The main quality of the reference gene is the constitutive expression under various experimental conditions, and also in pathological processes and in specific tissues.

It is known that upon carcinogenesis the expression of many genes, including some housekeeping genes, altered. This creates problems when searching for the reference genes for qPCR normalization, as there are no reference genes universal for all types of tumors [5]. Such genes must be validated, according to a tumor type and experimental conditions. Moreover, the features of their expression should also be considered. This is especially important for the low-expressed genes, which are often the subject of research, due to the peculiarity of their functions in physiological and pathological processes.

The validation of the reference genes for prostate tumors, lymph nodes from patients with prostate cancer and also prostate cancer cell lines resulted in the creation of a set of genes, namely $T B P, H P R T 1, A L A S 1, T U B A 1 B$, $G A P D H$ and $B 2 M$ that are expressed constitutively in prostate cancer and normal tissues, making them suitable for qPCR normalization [6-9].

In the present work, we used four reference genes (TBP, HPRT1, ALAS1, TUBA1B) in different combinations - from 1 to 4 genes, to compare the qPCR results after normalization.

\section{Materials and Methods}

Collection of prostate tissues. The samples of cancer tissues and conventional normal tissues (CNT, taken from the other prostate lobe outside of the tumor) were frozen in the liquid nitrogen immediately after surgical resection at the National Cancer Institute (Kyiv, Ukraine). Benign prostate tumors (prostate adenoma samples) were collected at the Institute of Urology (Kyiv, Ukraine) after radical prostatectomy and frozen as described above. All samples were collected in accordance with the Declaration of Helsinki and the guidelines, issued by an Ethic Committee of the Institute of Urology of National Academy of Medical Sciences of Ukraine and of the National Cancer Institute of National Academy of Sciences of Ukraine (NASU), and the Ethic Committee of the Institute of Molecular biology and genetics of NASU. Experimental studies were conducted, using 37 prostate adenocarcinoma samples of different Gleason scores and at various stages; 37 corresponding conventional normal tissue (CNT) samples; and 20 samples of adenomas [10,11]. The tumor samples were characterized, according to the International System of Classification of Tumors, based on the tumor-node-metastasis (TNM) and the World Health Organization (WHO) criteria. The clinical characteristics of the tumors were described earlier $[10,11]$.

Total RNA isolation and cDNA synthesis. 50-70 mg of frozen prostate tissues were homogenized to a powder in liquid nitrogen. Total RNA was isolated, using TRI-reagent (Sigma-Aldrich, USA). The concentration of the isolated total RNA was assessed, using a spectrophotometer (NanoDrop Technologies Inc. USA). The quality of RNA was deter- 
mined by electrophoresis in a $1 \%$ agarose gel by band intensity of $28 \mathrm{~S}$ and $18 \mathrm{~S}$ rRNA (28S/18S ratio). $1 \mu \mathrm{g}$ of the total RNA was treated with RNase-free DNase I (Thermo Fisher Scientific, USA); cDNA was synthetized, using RevertAid H-Minus M-MuLV Reverse Transcriptase (Thermo Fisher Scientific, USA).

Quantitative PCR (qPCR). Relative gene expression (RE) levels of 23 genes were assessed, using the Bio-Rad CFX96 Real-Time PCR Detection System (USA) with Maxima SYBR Green Master mix (Thermo Fisher Scientific, USA). The qPCR cycling conditions were as follows: $95^{\circ} \mathrm{C} \times 10^{\prime},\left(95^{\circ} \mathrm{C} \times 15^{\prime \prime}, 60^{\circ} \mathrm{C}\right.$ $\times 30^{\prime \prime}, 72^{\circ} \mathrm{C} \times 30^{\prime \prime}$ for 40 cycles). Primers were selected with the help of a "qPrimerDepot A quantitative real time PCR primer database" (http://primerdepot.nci.nih.gov) and PrimerBLAST (https://www.ncbi.nlm.nih.gov/tools/ primer-blast/).

Four reference genes - TBP, HPRT1, $A L A S 1$ and TUBA1B - were used for normalization of RE levels [4, 7] in different combinations: 1 reference gene (1 ref) - TBP, 2 reference genes ( 2 ref $)-T B P$ and $H P R T$ and 4 reference genes (4 ref) - TBP, HPRT, ALAS1 and $T U B A 1 B$. RE levels were calculated, using two common methods $\left(2^{-\Delta \mathrm{Ct}}\right.$ and $\left.2^{-\Delta \Delta \mathrm{Ct}}\right)$ described earlier [10-12].

Statistical analysis. The KolmogorovSmirnov test was used to analyze the normality of distribution. The RE levels in prostate adenocarcinoma and paired CNT were compared, using the Wilcoxon Matched Pairs test. $\mathrm{RE}$ fold differences in $2^{-\Delta \Delta \mathrm{Ct}}$ model were considered significant, when expression changed more or less, than 2 folds. The Fisher exact test was used to monitor differences between experimental groups. The differences between experimental groups (adenocarcinomas, CNT and adenomas) were determined by KruskalWallis test with following tests for multiple comparisons. The Dunn-Bonferoni post-hoc test was performed to determine RE differences between pairs of prostate samples under multiple gene comparisons [13]. The Benjamini-Hochberg procedure was used to adjust a false discovery rate (FDR) set at $0.10-0.25$, when multiple comparisons were performed [14].

\section{Results}

$\mathrm{RE}$ of 23 genes, representing markers of cancer-associated fibroblasts (CAF) (the CAF gene group), tumor-associated macrophages (TAM) (the TAM gene group) and inflammation-associated genes (the INF gene group) have been determined. Genes were divided also by RE level into three groups: showing a high expression ( $\mathrm{Ct}<20$ cycles), the moderate expression $(\mathrm{Ct}=20-29$ cycles $)$ and the low expression $(\mathrm{Ct}>29$ cycles).

The reference genes $A L A S 1$ and TUBA1B showed a high level of expression, whereas $T B P$ and HPRT were expressed at a moderate level. TBP demonstrated the lowest expression level among the references. Only three genes ( $A C T A 2, M S M B$ and $H L A-G$ ) out of 23 studied demonstrated high RE levels. 10 genes were expressed at a moderate level and 10 - at low level of expression.

A theoretical calculation of a hypothetical deviation of the RE of reference genes expressed at high and low levels was developed, taking $0.5 \mathrm{Ct}$ as a hypothetical error. RE of the studied genes was calculated, using the $2^{-\Delta \mathrm{Ct}}$ method (Table 1). 
Table 1. Calculation of changes in RE of investigated (Inv) and reference (Ref) genes, expressed at different levels (high (h), moderate (m) and low (l)), when the hypothetical error was $0.5 \mathrm{Ct}$ (e).

\begin{tabular}{|l|c|c|c|}
\hline \multicolumn{1}{|c|}{ Genes } & Ct Ref & Inv1 low & Inv2 high \\
\hline Ct Inv & & 31 & 17 \\
\hline RE /Ref h & 15 & 0.000015 & 0.250 \\
\hline RE /Ref he & 15.5 & 0.000022 & 0.354 \\
\hline RE /Ref m & 25 & 0.016 & 256.000 \\
\hline RE /Ref me & 25.5 & 0.022 & 362.039 \\
\hline RE /Ref I & 32 & 2.000 & 32768.000 \\
\hline RE /Ref le & 32.5 & 2.828 & 46340.950 \\
\hline $\begin{array}{l}\text { RE fold changes } \\
\text { Ref he/h }\end{array}$ & & 1.414 & 1.414 \\
\hline $\begin{array}{l}\text { RE fold changes } \\
\text { Ref me/m }\end{array}$ & & 1.414 & 1.414 \\
\hline $\begin{array}{l}\text { RE fold changes } \\
\text { Ref le/l }\end{array}$ & & 1.414 & 1.414 \\
\hline
\end{tabular}

Notes: Ref $\mathbf{h}$ - high expression of the reference gene, Ref he Ref $\mathrm{h}$ with $0.5 \mathrm{Ct}$ error, Ref $\mathbf{m}$ - moderate expression of the reference gene, Ref me - Ref m with 0.5 Ct error, Ref $\mathbf{l}-$ low expression of the reference gene, Ref le - Ref with $0.5 \mathrm{Ct}$ error.

Our calculations showed that the RE deviation with an error of $0.5 \mathrm{Ct}$ for reference genes was the same (1.414) for all analyzed genes, regardless expression levels of the reference genes (Table 1). This data indicates the importance of the constitutive expression of the reference gene when comparing RE of the analysed and the reference genes.

The experimental data calculated, using the $2^{-\Delta \Delta \mathrm{Ct}}$ model, showed statistical significant differences between the paired T/CNT in one reference group (17 out of 23 investigated genes) (Table 2).

A complete match of statistical data was observed for all three reference groups for 16 out of 23 genes. Eleven genes beyond 16 showed significant changes of RE in all three reference groups; 7 of these genes were expressed at high and moderate levels. Divergences of RE were observed for 7 genes in 10 comparative groups, 6 of which showed low expression. Thus, the threshold value of matching differences for highly and moderately expressed genes was set at 25-30\% (10-11 samples out of 37), whereas for low expressed genes the value should be no less, than $35 \%$ (more than 13 samples out of 37 ), to avoid possible expression deviations of the reference genes and minimize the influence of qPCR reaction inhibitors for PCR analysis of low-expressed genes.

$\mathrm{RE}$ values were investigated using the $2^{-\Delta \mathrm{Ct}}$ method for three sets of the samples:

1. The TNA set -3 total sample groups: Adenocarcinomas $(\mathrm{T}, \mathrm{n}=37), \mathrm{CNT}(\mathrm{N}$, $\mathrm{n}=37)$ and adenomas $(\mathrm{A}, \mathrm{n}=20)$;

2 . The cancer stage set -5 groups of samples at the various tumor stages: adenocarcinomas of stage 1-2 (T1-2, $\mathrm{n}=28)$, adenocarcinomas of stage 3-4 (T3-4, $\mathrm{n}=9)$, CNT of stage 1-2 (N1-2, n= 28), CNT of stage 3-4 (N3-4, n =9), adenomas (A, $\mathrm{n}=20$ );

3. A set divided by the GL -7 groups: adenocarcinomas GL $<7(\mathrm{~T}<7, \mathrm{n}=11)$, adenocarcinomas $\mathrm{GL}=7(\mathrm{~T}=7, \mathrm{n}=9)$, adenocarcinomas $\mathrm{GL}>7(\mathrm{~T}>7, \mathrm{n}=17)$, CNT GL $<7(\mathrm{~N}<7, \mathrm{n}=11), \mathrm{CNT}$ $\mathrm{GL}=7(\mathrm{~N}=7, \mathrm{n}=9), \mathrm{CNT} \mathrm{GL}>7$ $(\mathrm{N}>7, \mathrm{n}=17)$, adenomas $(\mathrm{A}, \mathrm{n}=20)$.

Fold changes in RE for genes with statistically significant differences between sample groups (with normalization by 3 reference types) and p-values are shown in Table $3 A-C$.

A high similarity was found for all three reference groups with different types of group- 
Table 2. Numbers of adenocarcinoma samples with changes in RE ( $2^{-\mathrm{ddCt}}$ model), normalized with the use of 1,2 or 4 reference genes

\begin{tabular}{|c|c|c|c|c|c|c|c|}
\hline \multirow{2}{*}{ Gene group } & \multirow{2}{*}{ Genes } & \multicolumn{2}{|c|}{1 reference gene } & \multicolumn{2}{|c|}{2 reference genes } & \multicolumn{2}{|c|}{4 reference genes } \\
\hline & & $>2.01$ & $<0.49$ & $>2.01$ & $<0.49$ & $>2.01$ & $<0.49$ \\
\hline \multirow{8}{*}{ CAF } & ACTA2 & 9 & 4 & 9 & 3 & $7 \&$ & 3 \\
\hline & CXCL14 & 19 & 3 & 19 & 4 & 17 & 4 \\
\hline & $C T G F$ & 12 & 0 & 12 & 2 & 11 & 1 \\
\hline & HIF1A & 5 & 0 & 3 & 0 & 3 & 0 \\
\hline & $S 100 A 4$ & 3 & 6 & 3 & 5 & 2 & 5 \\
\hline & THY1 & 9 & 3 & 9 & 2 & $7 \&$ & 1 \\
\hline & CXCL12 & 4 & 7 & 5 & 6 & 4 & 6 \\
\hline & FAP & 12 & 0 & 11 & 1 & 13 & 1 \\
\hline \multirow{6}{*}{ TAM } & $C D 68$ & 8 & 4 & 6 & 3 & 5 & 6 \\
\hline & $C D 163$ & 14 & 5 & 12 & 6 & 11 & 5 \\
\hline & CCR4 & 8 & 9 & 6 & 8 & 5 & 10 \\
\hline & CCL17 & 8 & 6 & 9 & 8 & 10 & 8 \\
\hline & CCL22 & 10 & 8 & 6 & 7 & 6 & 6 \\
\hline & $\operatorname{NOS} 2 A$ & 7 & 16 & 6 & 13 & 4 & 15 \\
\hline \multirow{9}{*}{ INF } & $M S M B$ & 6 & 10 & 5 & 10 & 6 & 9 \\
\hline & $H L A-G$ & 2 & 3 & 3 & 4 & 4 & 2 \\
\hline & IRF1_T1 & 3 & 6 & 4 & 7 & 3 & 6 \\
\hline & IL1R1_T17 & 1 & 11 & 1 & 8 & 1 & 8 \\
\hline & $C I A S$ & 4 & 6 & 4 & 6 & 3 & 5 \\
\hline & CTLA4 & 5 & 11 & 8 & 12 & 6 & 7 \\
\hline & ILIRL1 & 2 & 11 & 3 & 8 & 3 & 7 \\
\hline & $I L 2 R A$ & 8 & 8 & 8 & 7 & 7 & 6 \\
\hline & $K L R K$ & 8 & 10 & 8 & 9 & 7 & 4 \\
\hline
\end{tabular}

Notes: statistically significant differences between T/CNT, calculated, using the Fisher exact test with correction on multiple comparisons, FDR $=0.2$ are shown in bold (black and red); in black (bold) - statistically significant differences, that have a complete match for all groups of reference genes; in red (bold) -divergences of statistical results between reference groups; \& - significant differences with FDR $=0.2$; green boxes - highly expressed genes; white boxes - moderately expressed genes; pink boxes - low expressed genes.

ing of analyzed samples (> $82 \%$ - TNA group, $69 \%$ - Cancer stage group, $64.5 \%$ - GL group). 10 out of 23 genes in the TNA sample groups showed significant differences in RE in 17 pairs (Table $3 A$ ). No similarity was observed for the 3 reference group normalization in 3 sample groups of TNA (17.65\%) with RE fold changes less than 1.7 times.

Another grouping type (by tumor stages) (Table 3B) demonstrated significant differences in RE for 14 genes in 45 pairs of sample groups. No similarity in the 3 reference group 
G. V. Gerashchenko, E. O. Stakhovsky, L. I. Chashchina et al.

Table 3. Differences in the fold changes and p-values of RE differences between pairs of groups, calculated by the Dunn-Bonferroni post hoc method for multiple comparisons, normalized to various reference genes in prostate tumors, grouped by TNA (A), stages (B), Gleason score (C).

$A$.

\begin{tabular}{|c|c|c|c|c|c|c|c|c|}
\hline \multirow{2}{*}{$\begin{array}{l}\text { Gene } \\
\text { group }\end{array}$} & \multirow{2}{*}{ Gene } & \multirow{2}{*}{ Pairs of groups } & \multicolumn{3}{|c|}{ Fold changes } & \multicolumn{3}{|c|}{$\mathrm{p}$-value } \\
\hline & & & $1 \mathrm{ref}$ & 2 ref & $4 \mathrm{ref}$ & $1 \mathrm{ref}$ & 2 ref & 4 ref \\
\hline \multirow{9}{*}{ CAF } & \multirow{3}{*}{ CXCL14 } & $\mathrm{T} / \mathrm{A}$ & 7.80 & 6.57 & 6.03 & 0.000 & 0.000 & 0.000 \\
\hline & & $\mathrm{T} / \mathrm{N}$ & 3.26 & 2.32 & 2.27 & 0.011 & 0.019 & 0.025 \\
\hline & & N/A & 2.39 & 2.83 & 2.66 & 0.005 & 0.002 & 0.003 \\
\hline & \multirow{2}{*}{$C T G F$} & $\mathrm{~T} / \mathrm{A}$ & 2.06 & 2.43 & 2.51 & 0.001 & 0.000 & 0.001 \\
\hline & & $\mathrm{T} / \mathrm{N}$ & 1.58 & 1.51 & 1.50 & 0.036 & 0.041 & $0.055^{\&}$ \\
\hline & THY1 & $\mathrm{T} / \mathrm{A}$ & 1.87 & 1.79 & 1.71 & 0.017 & 0.006 & 0.011 \\
\hline & \multirow{2}{*}{ CXCL12 } & $\mathrm{T} / \mathrm{A}$ & 0.35 & 0.39 & 0.45 & 0.000 & 0.000 & 0.000 \\
\hline & & N/A & 0.38 & 0.40 & 0.41 & 0.001 & 0.000 & 0.000 \\
\hline & $F A P$ & $\mathrm{~T} / \mathrm{A}$ & 1.63 & 1.78 & 1.91 & 0.049 & 0.024 & 0.015 \\
\hline \multirow{5}{*}{ TAM } & CD163 & $\mathrm{T} / \mathrm{A}$ & 2.14 & 1.68 & 1.39 & 0.045 & 0.129 & 0.250 \\
\hline & \multirow{2}{*}{ CCR4 } & $\mathrm{T} / \mathrm{A}$ & 0.57 & 0.56 & 0.54 & 0.037 & 0.009 & 0.002 \\
\hline & & N/A & 0.78 & 0.71 & 0.70 & 0.149 & $0.054^{\&}$ & 0.040 \\
\hline & \multirow{2}{*}{ CCL17 } & $\mathrm{T} / \mathrm{A}$ & 2.12 & 1.99 & 2.09 & 0.004 & 0.009 & 0.015 \\
\hline & & N/A & 1.77 & 1.71 & 1.51 & 0.016 & 0.038 & 0.065 \\
\hline \multirow{3}{*}{ INF } & IL1RI & $\mathrm{T} / \mathrm{A}$ & 0.69 & 0.52 & 0.51 & 0.031 & 0.023 & 0.005 \\
\hline & \multirow{2}{*}{ CTLA4 } & $\mathrm{T} / \mathrm{A}$ & 2.40 & 2.13 & 2.16 & 0.043 & 0.023 & 0.016 \\
\hline & & N/A & 2.72 & 3.12 & 2.61 & 0.001 & 0.002 & 0.003 \\
\hline
\end{tabular}

B.

\begin{tabular}{|c|c|c|c|c|c|c|c|c|}
\hline \multirow{2}{*}{$\begin{array}{l}\text { Gene } \\
\text { group }\end{array}$} & \multirow{2}{*}{ Gene } & \multirow{2}{*}{ Pairs of groups } & \multicolumn{3}{|c|}{ Fold changes } & \multicolumn{3}{|c|}{ p-value } \\
\hline & & & $1 \mathrm{ref}$ & $2 \mathrm{ref}$ & $4 \mathrm{ref}$ & $1 \mathrm{ref}$ & $2 \mathrm{ref}$ & 4 ref \\
\hline \multirow{10}{*}{ CAF } & \multirow{4}{*}{ CXCL14 } & T1-2/A & 6.48 & 6.4 & 5.84 & 0 & 0 & 0 \\
\hline & & T3-4/A & 17.82 & 7.66 & 6.98 & 0 & 0 & 0 \\
\hline & & N3-4/A & 6.09 & 6.27 & 5.55 & 0.008 & 0.004 & 0.004 \\
\hline & & T1-2/N1-2 & 3.56 & 2.75 & 2.66 & 0.036 & 0.06 & 0.089 \\
\hline & \multirow{2}{*}{$C T G F$} & T1-2/A & 2.08 & 2.48 & 2.33 & 0.001 & 0.001 & 0.005 \\
\hline & & T1-2/N3-4 & 3.31 & 2.22 & 2.06 & 0.001 & 0.006 & 0.028 \\
\hline & \multirow{4}{*}{ HIF1A } & T1-2/T3-4 & 2.47 & 2.83 & 1.92 & 0.001 & 0.003 & 0.008 \\
\hline & & T1-2/N3-4 & 2.65 & 3.03 & 2.14 & 0 & 0.001 & 0.001 \\
\hline & & T3-4/A & 0.43 & 0.4 & 0.49 & 0.012 & 0.012 & 0.01 \\
\hline & & N1-2/N3-4 & 2.02 & 2.49 & 2.03 & 0.03 & 0.026 & 0.012 \\
\hline
\end{tabular}


A role of expression level of reference and investigated genes in prostate tumors for qPCR analysis

continued Table $3 B$

\begin{tabular}{|c|c|c|c|c|c|c|c|c|}
\hline \multirow{2}{*}{$\begin{array}{l}\text { Gene } \\
\text { group }\end{array}$} & \multirow{2}{*}{ Gene } & \multirow{2}{*}{ Pairs of groups } & \multicolumn{3}{|c|}{ Fold changes } & \multicolumn{3}{|c|}{$\mathrm{p}$-value } \\
\hline & & & $1 \mathrm{ref}$ & 2 ref & $4 \mathrm{ref}$ & $1 \mathrm{ref}$ & 2 ref & 4 ref \\
\hline \multirow{7}{*}{ CAF } & HIF1A & N3-4/A & 0.4 & 0.38 & 0.44 & 0.005 & 0.004 & 0.001 \\
\hline & THY1 & T1-2/A & 1.69 & 2.28 & 1.8 & 0.026 & 0.013 & 0.041 \\
\hline & \multirow{4}{*}{ CXCL12 } & $\mathrm{T} 1-2 / \mathrm{A}$ & 0.46 & 0.41 & 0.41 & 0.002 & 0.001 & 0 \\
\hline & & T3-4/A & 0.41 & 0.41 & 0.47 & 0.008 & 0.028 & 0.034 \\
\hline & & $\mathrm{N} 1-2 / \mathrm{A}$ & 0.54 & 0.45 & 0.43 & 0.022 & 0.011 & 0.001 \\
\hline & & N3-4/A & 0.41 & 0.34 & 0.37 & 0.004 & 0.007 & 0.002 \\
\hline & $F A P$ & T1-2/A & 1.32 & 1.85 & 1.94 & $0.051^{\&}$ & 0.043 & $0.057^{\&}$ \\
\hline \multirow{23}{*}{ TAM } & \multirow{3}{*}{ CD68 } & $\mathrm{T} 1-2 / \mathrm{T} 3-4$ & 4.51 & 2.96 & 2.75 & $0.056^{\&}$ & 0.021 & 0.082 \\
\hline & & T1-2/N3-4 & 4.01 & 3.96 & 1.34 & 0.04 & 0.033 & 1 \\
\hline & & T3-4/N1-2 & 0.22 & 0.34 & 0.34 & 0.111 & 0.048 & 0.166 \\
\hline & \multirow{6}{*}{$C D 163$} & T1-2/T3-4 & 0.07 & 0.08 & 0.07 & 0.045 & 0.042 & 0.016 \\
\hline & & T1-2/N3-4 & 0.1 & 0.11 & 0.09 & 0.114 & 0.083 & 0.05 \\
\hline & & T3-4/A & 17.8 & 17.13 & 17.51 & 0.002 & 0.005 & 0.005 \\
\hline & & T3-4/N1-2 & 12.78 & 15.26 & 17.81 & 0.006 & 0.005 & 0.003 \\
\hline & & N1-2/N3-4 & 0.11 & 0.1 & 0.07 & 0.019 & 0.011 & 0.01 \\
\hline & & N3-4/A & 12.84 & 11.42 & 13.46 & 0.006 & 0.011 & 0.017 \\
\hline & \multirow{4}{*}{ CCR4 } & T1-2/T3-4 & 2.55 & 2.08 & 1.99 & 0.06 & 0.049 & 0.062 \\
\hline & & T3-4/A & 0.26 & 0.34 & 0.34 & 0.002 & 0 & 0 \\
\hline & & T3-4/N1-2 & 0.31 & 0.45 & 0.48 & 0.04 & 0.027 & 0.037 \\
\hline & & N3-4/A & 0.55 & 0.56 & 0.59 & 0.105 & 0.034 & 0.203 \\
\hline & \multirow{5}{*}{ CCL17 } & T1-2/N3-4 & 0.2 & 0.16 & 0.12 & 0.023 & 0.014 & 0.009 \\
\hline & & T3-4/A & 8.49 & 8.59 & 9.52 & 0.006 & 0.005 & 0.004 \\
\hline & & T3-4/N1-2 & 7.12 & 7.41 & 8.82 & 0.113 & 0.05 & 0.023 \\
\hline & & N1-2/N3-4 & 0.11 & 0.1 & 0.07 & 0.001 & 0.001 & 0 \\
\hline & & N3-4/A & 10.41 & 11.05 & 14.72 & 0 & 0 & 0 \\
\hline & \multirow{3}{*}{ CCL22 } & T1-2/T3-4 & 3 & 3.15 & 2.7 & 0.004 & 0.006 & 0.044 \\
\hline & & T1-2/A & 1.93 & 2.19 & 2.32 & 0.012 & 0.025 & 0.039 \\
\hline & & T3-4/N1-2 & 0.41 & 0.39 & 0.47 & 0.015 & 0.032 & 0.156 \\
\hline & \multirow{2}{*}{$N O S 2 A$} & T3-4/N1-2 & 0.16 & 0.23 & 0.16 & 0.014 & 0.013 & 0.008 \\
\hline & & N1-2/N3-4 & 5.12 & 5.73 & 4.63 & 0.039 & 0.047 & 0.125 \\
\hline
\end{tabular}


G. V. Gerashchenko, E. O. Stakhovsky, L. I. Chashchina et al.

continued Table $3 B$

\begin{tabular}{|c|c|c|c|c|c|c|c|c|}
\hline \multirow{2}{*}{$\begin{array}{l}\text { Gene } \\
\text { group }\end{array}$} & \multirow{2}{*}{ Gene } & \multirow{2}{*}{ Pairs of groups } & \multicolumn{3}{|c|}{ Fold changes } & \multicolumn{3}{|c|}{ p-value } \\
\hline & & & $1 \mathrm{ref}$ & 2 ref & 4 ref & $1 \mathrm{ref}$ & 2 ref & 4 ref \\
\hline \multirow{5}{*}{ INF } & \multirow{2}{*}{ ILIRI } & T3-4/A & 0.32 & 0.26 & 0.27 & 0.086 & 0.039 & 0.007 \\
\hline & & N3-4/A & 0.51 & 0.54 & 0.37 & 0.237 & 0.178 & 0.014 \\
\hline & \multirow{3}{*}{ CTLA4 } & T1-2/A & 2.33 & 2.32 & 2.25 & 0.127 & 0.047 & 0.047 \\
\hline & & $\mathrm{N} 1-2 / \mathrm{A}$ & 2.65 & 2.85 & 2.49 & 0.021 & 0.016 & 0.022 \\
\hline & & N3-4/A & 3.78 & 3.81 & 3.09 & 0.028 & 0.077 & 0.113 \\
\hline
\end{tabular}

C.

\begin{tabular}{|c|c|c|c|c|c|c|c|c|}
\hline \multirow{2}{*}{$\begin{array}{l}\text { Gene } \\
\text { group }\end{array}$} & \multirow{2}{*}{ Gene } & \multirow{2}{*}{ Pairs of groups } & \multicolumn{3}{|c|}{ Fold changes } & \multicolumn{3}{|c|}{ p-value } \\
\hline & & & $1 \mathrm{ref}$ & 2 ref & 4 ref & $1 \mathrm{ref}$ & 2 ref & $4 \mathrm{ref}$ \\
\hline \multirow{15}{*}{ CAF } & \multirow{4}{*}{ CXCL14 } & $\mathrm{T}<7 / \mathrm{A}$ & 4.47 & 4.86 & 3.74 & 0.022 & 0.016 & 0.058 \\
\hline & & $\mathrm{T}=7 / \mathrm{A}$ & 7.91 & 6.57 & 6.27 & 0 & 0 & 0 \\
\hline & & $\mathrm{T}>7 / \mathrm{A}$ & 8.61 & 8.07 & 7.56 & 0 & 0 & 0 \\
\hline & & $\mathrm{N}>7 / \mathrm{A}$ & 4.22 & 4.8 & 4.43 & 0.017 & 0.007 & 0.008 \\
\hline & \multirow{3}{*}{$C T G F$} & $\mathrm{~T}<7 / \mathrm{A}$ & 3.12 & 4.07 & 3.13 & 0.041 & 0.022 & 0.098 \\
\hline & & $\mathrm{T}=7 / \mathrm{A}$ & 3.19 & 2.87 & 2.57 & 0.005 & 0.011 & 0.027 \\
\hline & & $\mathrm{T}=7 / \mathrm{N}>7$ & 2.57 & 2 & 1.75 & 0.019 & 0.099 & 0.176 \\
\hline & \multirow{2}{*}{ HIF1A } & $\mathrm{T}=7 / \mathrm{T}>7$ & 2.45 & 2.36 & 2.14 & 0.001 & 0.002 & 0.004 \\
\hline & & $\mathrm{T}=7 \mathrm{~N}>7$ & 1.97 & 2.03 & 2.09 & 0.001 & 0.004 & 0.006 \\
\hline & THY1 & $\mathrm{T}<7 / \mathrm{A}$ & 1.96 & 2.59 & 1.78 & 0.078 & 0.026 & 0.098 \\
\hline & \multirow{5}{*}{ CXCL12 } & $\mathrm{T}<7 / \mathrm{A}$ & 0.56 & 0.56 & 0.48 & 0.222 & 0.176 & 0.009 \\
\hline & & $\mathrm{T}=7 / \mathrm{A}$ & 0.31 & 0.38 & 0.29 & 0.118 & 0.073 & 0.003 \\
\hline & & $\mathrm{T}>7 / \mathrm{A}$ & 0.33 & 0.37 & 0.43 & 0.001 & 0.001 & 0.001 \\
\hline & & $\mathrm{N}=7 / \mathrm{A}$ & 0.32 & 0.36 & 0.35 & 0.15 & 0.146 & 0.035 \\
\hline & & $\mathrm{N}>7 / \mathrm{A}$ & 0.34 & 0.35 & 0.37 & 0.004 & 0.003 & 0.001 \\
\hline \multirow{6}{*}{ TAM } & \multirow{3}{*}{ CCR4 } & $\mathrm{T}<7 / \mathrm{T}>7$ & 3 & 3.24 & 3.29 & 0.027 & 0.02 & 0.025 \\
\hline & & $\mathrm{T}>7 / \mathrm{A}$ & 0.42 & 0.39 & 0.34 & 0.005 & 0.001 & 0 \\
\hline & & $\mathrm{N}>7 / \mathrm{A}$ & 0.55 & 0.57 & 0.66 & 0.103 & 0.033 & 0.04 \\
\hline & \multirow{2}{*}{ CCL17 } & $\mathrm{T}>7 / \mathrm{A}$ & 3.18 & 2.93 & 3.39 & 0.002 & 0.003 & 0.004 \\
\hline & & $\mathrm{N}>7 / \mathrm{A}$ & 2.98 & 3.12 & 2.79 & 0.002 & 0.005 & 0.01 \\
\hline & CCL22 & $\mathrm{T}<7 / \mathrm{A}$ & 2.35 & 2.46 & 2.58 & 0.037 & 0.045 & 0.051 \\
\hline
\end{tabular}


continued Table 3C

\begin{tabular}{|c|c|c|c|c|c|c|c|c|}
\hline \multirow{2}{*}{$\begin{array}{l}\text { Gene } \\
\text { group }\end{array}$} & \multirow{2}{*}{ Gene } & \multirow{2}{*}{ Pairs of groups } & \multicolumn{3}{|c|}{ Fold changes } & \multicolumn{3}{|c|}{ p-value } \\
\hline & & & $1 \mathrm{ref}$ & $2 \mathrm{ref}$ & $4 \mathrm{ref}$ & $1 \mathrm{ref}$ & $2 \mathrm{ref}$ & $4 \mathrm{ref}$ \\
\hline \multirow{2}{*}{ TAM } & \multirow{2}{*}{$\operatorname{NOS} 2 A$} & $\mathrm{~T}>7 / \mathrm{N}=7$ & 0.1 & 0.13 & 0.15 & 0.004 & 0.001 & 0.002 \\
\hline & & $\mathrm{N}=7 / \mathrm{N}>7$ & 7.42 & 6.42 & 4.44 & $0.052^{\&}$ & 0.027 & 0.045 \\
\hline \multirow{8}{*}{ INF } & \multirow{2}{*}{ IL1R1 } & $\mathrm{T}>7 / \mathrm{A}$ & 0.39 & 0.41 & 0.37 & 0.059 & 0.027 & 0.006 \\
\hline & & $\mathrm{T}>7 / \mathrm{N}=7$ & 0.26 & 0.23 & 0.27 & 0.015 & 0.018 & 0.032 \\
\hline & \multirow{4}{*}{ CTLA4 } & $\mathrm{T}<7 / \mathrm{A}$ & 4.1 & 4.8 & 4.5 & 0.012 & 0.002 & 0.002 \\
\hline & & $\mathrm{T}<7 / \mathrm{T}>7$ & 2.25 & 2.81 & 2.68 & 0.125 & 0.031 & 0.031 \\
\hline & & $\mathrm{T}>7 / \mathrm{N}=7$ & 0.32 & 0.44 & 0.4 & 0.042 & 0.065 & 0.065 \\
\hline & & $\mathrm{N}=7 / \mathrm{A}$ & 5.62 & 3.92 & 4.18 & 0.004 & 0.006 & 0.006 \\
\hline & \multirow{2}{*}{$I L 2 R A$} & $\mathrm{~T}<7 / \mathrm{A}$ & 2.18 & 2.44 & 1.89 & 0.02 & 0.003 & 0.008 \\
\hline & & $\mathrm{T}<7 / \mathrm{T}>7$ & 0.2 & 0.12 & 0.09 & 0.075 & 0.006 & 0.061 \\
\hline
\end{tabular}

Notes: \& - significant differences with FDR $=0.2$; red $\mathrm{p}$-value; $-\mathrm{p}<0.05$ is considered as statistically significant; p-value $0.000-p<0.001$; white boxes - moderately expressed genes; pink boxes - low expressed genes

normalization was observed for 14 pairs of sample groups $(31 \%)$ with RE changes less than 3-4 folds.

Prostate cancers grouped by GL (Table 3C) showed significant changes in RE for 12 genes out of 23, for 31 pairs of samples. No similarity in the 3 reference group normalization was observed for 11 sample groups $(35.5 \%)$ with changes in RE less than 5 fold.

\section{Discussion}

Performed hypothetical calculations indicate that the expression of both, reference and analyzed genes does not influence the deviation (variation) in obtained RE, if the $2^{-\Delta \mathrm{Ct}}$ method was used. This confirms the need for constitutive expression of reference genes in all analyzed samples $[5,6]$. Some cautions concern the low expressed genes, for example, during PCR analysis the PCR inhibitors may increase. By PCR inhibitors we mean formed dimers of primers, non-specific products and loss in the activity of Tag-polymerase [15-17]. All these factors inadvertently impact the efficiency of PCR, thus, resulting in erroneous RE levels. This, in turn, leads to difficulties in assessment of the low expressed genes, regardless of the optimization of qPCR conditions. Especially, this is important if the reference genes are expressed at low levels. So, the low expressed genes should not be chosen as the reference.

Other parameters that impact RE are the values of fold changes and a proportion of the samples where the expression of a certain gene changed significantly. High heterogeneity of gene expression in prostate cancer samples [18] makes this impact more complicated. Noteworthy, in the cases, when fold change is high, the expression levels of the reference do not influence the calculated values, as shown by our results and literature data $[7,13]$. When we compared the changes lower than 2-fold or in a 
proportion of samples below $30 \%$ of all studied, even if differences in RE were statistically significant, we could get both, false positive and false negative results, namely differences could appear where they are not present, groups overlapped, etc. This impact became more evident, when the low expressing genes were analysed, using both methods, the $2^{-\Delta \mathrm{Ct}}$ and $2^{-\Delta \Delta \mathrm{Ct}}$.

The next important factor of the statistical analysis is the number of samples in a group [19]. This is supported by the data presented in this article. For example, the largest number of samples in groups (20 to 37 grouped samples (TNA group)) produced the lowest proportion of inconsistences of statistical results for all reference groups. Additionally, this amount of samples in groups demonstrated the highest rate of matching results $(82 \%)$ and the lowest threshold of fold changes ( 1.7 times) to observe the statistically significant differences between the analysed groups for all of reference genes.

The type of grouping is no less important, than the number of samples in groups. Obviously, the gene expression pattern correlates with the clinical and pathological characteristics, thus providing the possibility to define the genes with altered expression at a given stage of the disease (HIF 1A, CD68, CCL22, NOS2A1), or related to a specific GL score (HIF1A, CCL22, NOS2A, IL2RA1). Noteworthy, in the TNA group, that contained tissues, collected at the different stages of disease or tumors attributed with various GL score, the expression changes were nullified, due to a high RE deviation.

\section{Conclusions}

All three types of reference genes can be used for normalization of RE for prostate tumor samples. The differences in the expression levels of investigated and reference genes have no impact regardless usage of the $2^{-\Delta \mathrm{Ct}}$ and $2^{-\Delta \Delta \mathrm{Ct}}$ models; the constitutive expression of reference genes is the important parameter. Thus, the values of expression of the analysed genes, as well as RE value changes, the number of samples in groups and high heterogeneity of gene expression are important parameters for choosing the threshold level differences between the groups of samples for reliable data interpretation.

\section{REFERENCES}

1. Sanders R, Mason DJ, Foy CA, Huggett JF. Considerations for accurate gene expression measurement by reverse transcription quantitative PCR when analyzing clinical samples. Anal Bioanal Chem. 2014;406(26):6471-83.

2. Chen J, Zhao Z, Chen Y, Zhang J, Yan L, Zheng X, Liao $M$, Cao W. Development and application of a SYBR green real-time PCR for detection of the emerging avian leukosis virus subgroup K. Poult Sci. 2018;97(7):2568-2574.

3. Shi W, Wang $Y$, Ren X, Gao S, Hua X, Guo M, Tang L, Xu Y, Ren T, Li Y, Liu M. EvaGreen-based real-time PCR assay for sensitive detection of salmonid alphavirus. Mol Cell Probes. 2018;39:7-13.

4. Sharan RN, Vaiphei ST, Nongrum S, Keppen J, $K$ soo $M$. Consensus reference gene(s) for gene expression studies in human cancers: end of the tunnel visible? Cell Oncol (Dordr). 2015;38(6):419-31.

5. Dundas J, Ling $M$. Reference genes for measuring mRNA expression. Theory Biosci. 2012;131(4):215-23.

6. Ohl F, Jung $M, X u$, Stephan $C$, Rabien A, Burkhardt $M$, Nitsche A, Kristiansen $G$, Loening $S A$, Radonić A, Jung $K$. Gene expression studies in prostate cancer tissue: which reference gene should be selected for normalization? J Mol Med (Berl). 2005;83(12):1014-24.

7. Souza AF, Brum IS, Neto BS, Berger M, Branchi$n i G$. Reference gene for primary culture of prostate cancer cells. Mol Biol Rep. 2013;40(4):2955-62. 
8. Zhao H, Ma TF, Lin J, Liu LL, Sun WJ, Guo LX, Wang SQ, Otecko NO, Zhang YP. Identification of valid reference genes for mRNA and microRNA normalisation in prostate cancer cell lines. Sci Rep. 2018;8(1):1949.

9. Tsaur I, Renninger M, Hennenlotter J, Oppermann E, Munz M, Kuehs U, Stenzl A, Schilling D. Reliable housekeeping gene combination for quantitative PCR of lymph nodes in patients with prostate cancer. Anticancer Res. 2013;33(12):5243-8.

10. Gerashchenko GV, Mankovska OS, Dmitriev AA, Mevs LV, Rosenberg EE, Pikul MV, Marynychenko MV, Gry-zodub OP, Stakhovsky EO, Kashuba VI. Epithelial-mesenchymal transition related gene expression in prostate tumours. Biopolym Cell. 2017; 33(5): 335-55.

11. Mevs LV, Gerashchenko GV, Rosenberg EE, Pikul MV, Marynychenko MV, Gryzodub OP, Vozianov SO, Stak-hovsky EO, Kashuba VI. Detection of prostate specific ETS fusion transcripts in cancer samples. Biopolym Cell. 2017; 33(4): 256-67.

12. ivak KJ, Schmittgen TD. Analysis of relative gene expression data using real-time quantitative PCR and the 2(-Delta Delta C(T)) Method. Methods. 2001;25(4):402-8.

13. Schmidt U, Fuessel $S$, Koch R, Baretton GB, Lohse A, Tomasetti S, Unversucht S, Froehner M, Wirth MP, Meye A. Quantitative multi-gene expression profiling of primary prostate cancer. Prostate. 2006;66(14):1521-34.

14. Benjamini Y, Hochberg Y. Controlling the false discovery rate: a practical and powerful approach to multiple testing. J R Stat Soc. 1995; 57(1): 289-300.

15. Opel KL, Chung D, McCord BR. A study of PCR inhibition mechanisms using real time PCR. $J$ Forensic Sci. 2010;55(1):25-33.

16. Pionzio AM, McCord BR. The effect of internal control sequence and length on the response to PCR inhibition in real-time PCR quantitation. Forensic Sci Int Genet. 2014;9:55-60.

17. Schrader C, Schielke A, Ellerbroek L, Johne R. PCR inhibitors - occurrence, properties and removal. J Appl Microbiol. 2012;113(5):1014-26.

18. Cancer Genome Atlas Research Network. The molecular taxonomy of primary prostate cancer. Cell. 2015;163(4):1011-25.
19. Carlisle AJ, Prabhu VV, Elkahloun A, Hudson J, Trent JM, Linehan WM, Williams ED, EmmertBuck MR, Liotta LA, Munson PJ, Krizman DB. Development of a prostate cDNA microarray and statistical gene expression analysis package. $\mathrm{Mol}$ Carcinog. 2000;28(1):12-22.

\section{Роль рівнів експресії референсних} та досліджуваних генів при раку передміхурової залози у кПЛР аналізі

Г. В. Геращенко, Е. О. Стаховський, Л. I . Чащина, О. П. Гризодуб, В. І. Кашуба

Мета. Визначити профілі експресії пухлино-асоційованих генів у пухлинах передміхурової залози з використанням різних протоколів нормалізації (з одно-, дво- та чотириреференсними генами АБО з одним, двома та чотирма референсними генами) та оптимізувати комбінації референсних генів для розрахунку відносної експресії (BE) у раку передміхурової залози. Методи. Кількісною ПЛР (кПЛР) проаналізовано ВЕ 23 генів у 37 зразках тканин передміхурової залози (Т) з різними показниками Глісона та різними стадіями пухлин у порівнянні з 37 умовно-нормальними зразками тканини передміхурової залози (УНТ) та 20 зразками аденом передміхурової залози. Результати. Теоретичні розрахунки відхилення ВЕ не підтвердили впливу значень рівнів експресії на цей параметр ані у ВЕ референсного гена, ані у ВЕ досліджуваних генів. Експермиментальні дані, які були отримані, з використанням $2^{-\Delta \Delta \mathrm{Ct}}$ моделі, показали статистичні значущі відмінності у експресії 17 з 23 досліджуваних генів, при порівнянні парних T/ УНТ. Показники ВЕ, розраховані з використанням моделі 2- $\Delta \mathrm{Ct}$, показали високий рівень співпадіння статистичних даних у всіх групах референтних генів для груп аденокарциноми-УНТ-аденоми (понад 82 \%). Слід зазначити, у 69 \% випадків, а за показниками Глісона у $64,5 \%$. Висновки. Всі три типи референсних генів, як і було передбачено, можуть бути використані для нормалізації ВЕ у зразках пухлини передміхурової залози. Використання моделей $2^{-\Delta \mathrm{Ct}}$ або $2^{-\Delta \Delta \mathrm{Ct}}$ не має впливу на рівень ВЕ для референсних генів. Найважливішим фактором була їх стабільна експресія. Важливими параметрами для вибору порогу відмінностей рівнів експресії між групами з метою правильної 
інтерпретації даних є рівні експресії досліджуваних генів, величина зміни значень ВE, розмір вибірки та висока гетерогенність експресії.

К л ю ч о в і с л о в а: пухлини передміхурової залози, відносна експресія генів, валідація референсних генів, різні рівні експресії, низькоекспресовані гени.

\section{Роль уровней экспрессии референсных и исследуемых генов при раке простаты в кПЦР анализе}

А. В. Геращенко, Э. А. Стаховский, Л. И. Чащина, А. П. Гризодуб, В. И. Кашуба

Цель. Определить профили экспрессии ряда опухоль-ассоциированных генов в опухолях предстательной железы, используя различные протоколы нормализации (одним, двумя и четырьмя референсными генами) и оптимизировать комбинацию этих генов для рассчета относительной экспрессии (ОЭ) исследуемых генов при раке предстательной железы. Методы. Количественной ПЦР (кПЦР) було проанализировано ОЭ 23 генов в 37 образцах рака предстательной железы (Т) с различными показателем Глисона и на разных стадиях, в сравнении с 37 условно-нормальными образцами ткани простаты (УНТ) и 20 образцами аденом предстательной железы. Результаты. Теоретические расчеты отклонения ОЭ не подтвердили влияния величины уровней экспрессии на этот параметр ни в ОЭ референсного гена, ни в ОЭ исследуемых генов.
Экспериментальные данные, полученые с использованием 2- $\Delta \Delta \mathrm{Ct}$ модели, показали статистически значимые различия экспрессии у 17 из 23 исследованных генов при сравнении парных Т/УНТ. ОЭ, рассчитанные с использованием модели $2^{-\Delta \mathrm{Ct}}$, показали высокий уровень совпадений статистических данных во всех группах референсных генов для групп аденокарциномы-УНТ-аденомы (более 82 \%). Следует отметить, что при разделении по стадиям совпадение статистических данных наблюдалось в 69 \% случаев, а по показателю Глисона - в 64,5 \%. Выводы. Все три типа референсных генов, как и ожидалось, могут быть использованы для нормализации ОЭ в образцах опухолей простаты. Использование моделей $2^{-\Delta \mathrm{Ct}}$ или $2^{-\Delta \Delta \mathrm{Ct}}$ не показало влияния различий в уровнях ОЭ для референсных генов. Наиболее важным фактором была их стабильная экспрессия. При выборе порога уровней экспрессии между группами с целью правильной интерпретации данных важными параметрами являются уровни экспрессии исследуемых генов, величина изменения значений ОЭ, размер выборки и высокая гетерогенность экспрессии.

К л юч в в е с л о а: опухоли предстательной железы, относительная экспрессия генов, валидация референсных генов, различные уровни экспрессии, низкоэкспрессированные гены.

Received 01.02.2018 